\title{
POLÍTICA PÚBLICA E CONFLITO NO ESPAÇO URBANO: DISPUTAS DA PATRIMONIALIZAÇÃO NO RIO DE JANEIRO ${ }^{1}$
}

\author{
INÁ ELIAS DE CASTRO² \\ Universidade Federal do Rio de Janeiro
}

Resumo: A análise aqui proposta tem como ponto de partida conceitual o fato de que a ocupação do espaço é por definição conflituosa, tendo em vista os interesses diferenciados daqueles que dele se apropriam. Este texto resulta da pesquisa sobre o problema da política de patrimonialização e discute as nuanças do debate sobre o conflito de interesses no espaço urbano do Rio de Janeiro, a partir dos problemas e das ações da política municipal de preservação do patrimônio cultural na cidade. A questão levantada foi como em um espaço urbano historicamente projetado pelos interesses do capital imobiliário e da propriedade privada houve a possibilidade de se realizar uma intervenção que contrariou em grande medida tais interesses. O objeto de análise é a Área de Proteção do Ambiente Cultural (APAC) do bairro do Leblon, pelo caráter paradigmático das questões envolvidas no projeto da Prefeitura.

Palavras-chave: Política Urbana; Rio de Janeiro; APAC Leblon; Patrimônio Cultural.

\section{PUBLIC POLICY AND CONFLICT IN URBAN SPACE: DISPUTES OVER HERITAGE RECOGNITIONIN RIO DE JANEIRO}

Abstract: The analysis proposed here has as a conceptual starting point the notion that the occupation of space is by definition conflictive, with different interests among those who appropriate space. This article results from a research on the issue of heritage policy and discusses the nuances of the debate on conflicts of interest in urban area of Rio de Janeiro, from the problems and the actions of the municipal policy for preserving cultural heritage in the city. The question raised was: how, in an urban space historically designed by the interests of real estate capital and private property, was an intervention

\footnotetext{
${ }^{1}$ Versão modificada do texto apresentado originalmente no Colóquio Internacional Les Ruines de la Patrimonialization, Paris, 03/2015.

2 Professora Titular da UFRJ, pesquisadora do CNPq. Participa do Programa Cientista do Nosso Estado, da FAPERJ. Contato: inacastro@uol.com.br
} 
largely contradicting those interests ever possible? The object of analysis is the Cultural Environment Protection Area (APAC) in Leblon neighborhood, given the paradigmatic nature of the issues involved in the City Hall project.

Keywords: Urban Policy; Rio de Janeiro; Leblon APAC; Cultural Heritage.

A análise aqui proposta tem como ponto de partida conceitual que a ocupação do espaço é por definição conflituosa, tendo em vista os interesses diferenciados daqueles que dele se apropriam. Foi neste sentido mais geral das condições objetivas das sociedades modernas ao qual a pesquisa se orientou, considerando aquilo que, por princípio, evoca a necessidade de recursos institucionais para ordenar a vida em sociedade e o espaço por ela ocupado (CASTRO, 2011). Afinal, interesses privados precisam ser organizados tendo em vista o bem comum, ou aquilo que é aceito como tal. Sendo assim, interesses, conflitos e as muitas maneiras de acomodá-los fazem parte da agenda dos governos, especialmente sob as condições das modernas democracias. Mas é na cidade que esse problema ganha dimensão e visibilidade. Ambas favorecem o que Simmel (2013) chamou de "le creuset d'une transformations de nos experiences sensibles et de nos mentalités”3 ${ }^{3}$, referindo-se à metrópole como um fenômeno que não é apenas espaço físico e estrutura social, mas, sobretudo, experiências corporais que desenham paisagens sensíveis, as quais formam o quadro de vida metropolitano (SIMAY, 1989). Portanto, faz todo sentido identificar na luta pelo espaço também a defesa de interesses vinculados a bens simbólicos, especialmente se estes se referem a um valor difuso denominado qualidade de vida.

Este texto resulta de uma pesquisa exploratória sobre o problema da política de patrimonialização e discute as nuanças do debate sobre o conflito de interesses no espaço urbano do Rio de Janeiro, a partir dos problemas e das ações da política municipal de preservação do patrimônio cultural na cidade. A questão levantada foi: como em um espaço urbano historicamente projetado pelos interesses do capital imobiliário e da propriedade privada houve a possibilidade de se realizar uma intervenção que contrariou em grande medida esses interesses? O objeto de análise é a Área de Proteção do Ambiente Cultural (APAC) do bairro do Leblon, pelo caráter paradigmático das questões envolvidas no projeto da prefeitura. O ponto de partida é a política como modo de organizar interesses no espaço urbano e a política pública como forma de intervenção do poder público, que resulta da balança desse conflito.

Nesse sentido, a ação da Prefeitura, no início da década de 1980, para a criação das APACs no Rio de Janeiro - inspiradas pela política anterior de proteção ao ambiente natural da cidade, Áreas de Proteção Ambiental (APAs) - configurou-se como uma política urbana definida pelos atores sociais naquele momento com maior

3 Tradução livre: "o recipiente onde se transformam nossas experiências sensíveis e nossas mentalidades”. 
poder de influência sobre a gestão municipal, como técnicos, intelectuais, representantes de associações de moradores e vereadores; a partir de diretrizes que fixam como matéria de preservação o "ambiente cultural” de diferentes bairros, visando resguardar, no limite, a qualidade de vida urbana.

A escolha do plano do texto pode parecer estranha à primeira vista, uma vez que o problema central da discussão - o projeto e o debate sobre a APAC do bairro do Leblon - ficou na última parte. Antes de chegar lá, tratamos rapidamente a reforma urbana da área central da cidade no início do século XX, a invenção e reinvenções de Copacabana e as discussões sobre a necessidade de preservação do patrimônio cultural das cidades, fortalecida na esteira das políticas de partrimonialização estimuladas pela UNESCO ${ }^{4}$ e, no Brasil, pelo Instituto do Patrimônio Histórico e Artístico Nacional (IPHAN).

A razão para a escolha - que se impôs ao longo das pesquisas bibliográficas e documentais, e da observação de campo - é justificada pelo argumento, o qual é considerado original, da relação entre as intervenções urbanísticas passadas, as drásticas mudanças sofridas pelo bairro de Copacabana nas primeiras décadas do século XX e o valor difuso do patrimônio cultural assumido como problema central nos projetos de preservação da Prefeitura do Rio de Janeiro, a partir dos anos 1980. Como se verá no desenrolar do texto, esses se constituem como elementos subjacentes ao discurso da elaboração do plano e posterior projeto da APAC.

$\mathrm{O}$ texto divide-se em quatro partes. Na primeira, é feita uma retrospectiva das políticas de renovação urbana no Rio de Janeiro desde o início do século XX, destacando a recorrência da valorização do novo frente ao velho, que deve ser substituído. Na segunda, dando continuidade à descrição sucinta desse processo, é abordado o caso do bairro de Copacabana, ícone do imaginário da cidade, cujos processos de rápida verticalização e adensamento, iniciados e consolidados ainda nas primeiras décadas do século XX, são percebidos na atualidade como exemplos a serem evitados. Na terceira, o problema do patrimônio cultural urbano e a necessidade da sua preservação são tratados como fundamentos da discussão sobre a APAC do bairro do Leblon. Na quarta parte, são apresentadas as questão desencadeadas a partir dos conflitos de interesses que o projeto de proteção da "cultura carioca” do bairro trouxe, sendo identificadas e analisadas as múltiplas dimensões desses conflitos.

\section{Rio de Janeiro: imaginário da renovação}

A cidade do Rio de Janeiro foi capital da colônia portuguesa a partir de 1763 e do Império Colonial Português de 1808 a 1821, período da invasão de Portugal pelas tropas de Napoleão Bonaparte. A partir de 1822, ano da independência do Brasil, até

\footnotetext{
${ }^{4}$ Organização das Nações Unidas para Educação, Ciência e Cultura.
} 
1889, ano da proclamação da república, a cidade foi capital do Império Brasileiro. No período republicano, a cidade foi a capital do país até 1960, quando a sede do governo federal foi transferida para Brasília. Apesar de ter sido capital por apenas dois séculos dos 4,5 séculos da existência do país, as benesses à cidade geradas por tal condição foram acrescidas ainda pelos 13 anos da presença da corte portuguesa através da apropriação de parte da riqueza gerada pela exploração de metais e pedras preciosas das “minas gerais”, no século XVII, e pela exportação de café, no século XIX -, os quais deixaram marcas que ainda se fazem sentir.

A cidade tornou-se o ícone da nação e foi,

ao lado de Paris, a cidade mais retratada durante todo o século XIX. Além do olhar estrangeiro, que construiu a paisagem dos trópicos, o Brasil e o Rio de Janeiro, em particular, contaram com a presença de um Imperador fotógrafo (OLIVEIRA, 2002, p. 156).

Além disso, a vinda da família real trouxe ao Rio de Janeiro uma classe social até então desconhecida, a nobreza, e com ela novas necessidades materiais que se impuseram a uma sociedade e a um espaço pouco diferenciados, cuja população era na maioria escravos e o comércio era a atividade mais importante, dominado por uma reduzida elite econômica (ABREU, 1987, p. 35).

A riqueza gerada pela atividade cafeeira na segunda metade do século XIX atraiu trabalhadores livres e investimentos estrangeiros que rapidamente transformaram o espaço urbano. As muitas ilustrações deixadas por Debret ${ }^{5}$ gravaram momentos importantes do cotidiano da sociedade e, de modo arguto, as características da divisão social na cidade. $\mathrm{O}$ artista francês captou as mudanças que começaram a se impor ao espaço físico e social. Mas, foi no início do século XX que importantes reformas urbanas com objetivo de sanear e modernizar a cidade foram implementadas, abrindo novos caminhos para a expansão e a diferenciação espacial da população: a elite para a zona sul da cidade e os pobres para a zona norte (ABREU, 1987, p. 36).

A reforma urbana mais importante, de 1903 a 1906, foi fortemente influenciada pelo ideário das intervenções em Paris realizadas por Haussmann, entre 1852 e 1870 (FREITAG, 2006; LARBODIÈRE, 2012; CHOAY, 2014). No Rio de Janeiro, o objetivo da reforma era a valorização dos espaços centrais para facilitar a livre circulação, sendo, para isso, necessário erradicar os cortiços e os imóveis degradados onde a população pobre residia. Quarteirões inteiros foram demolidos, morros foram arrasados e vielas antigas e tortuosas deixaram de existir no cenário carioca. Era o "Bota Abaixo", expressão popular que ganhou força devido à

\footnotetext{
${ }^{5}$ Jean-Baptiste Debret Paris (1768 - 1848) integrou a Missão Artística Francesa (1817), fundou no Rio de Janeiro uma academia de Artes e Ofícios, mais tarde a Academia Imperial de Belas Artes.
} 
quantidade de demolições na cidade. Nos anos 1920, estas transformações radicais continuam e, com o arrasamento do Morro do Castelo, todo o núcleo histórico, testemunho da fundação da cidade, desapareceu. Com o material descartado do morro fez-se uma grande praça, símbolo dessa modernidade e das novas sociabilidades - a Praça Paris, inaugurada em 1929. E a capital federal, antes uma cidade imunda, tornou-se "moderna”, possuindo ruas e praças "civilizadamente" mais largas, arborizadas e de arquitetura refinada, nos moldes europeus, pelo menos nas áreas centrais (ABREU, 1987). A tradição típica da modernidade, de que o novo é sempre melhor que o antigo (GOMES, 1996), foi desde então o emblema das intervenções urbanas na cidade, no mínimo até o final do século XX.

Durante os séculos XIX e XX, muitas gestões da cidade foram marcadas pelo signo da renovação. As reformas urbanas vinham impregnadas pela perspectiva da cidade como vitrine da nação e pela necessidade de mantê-la atualizada em relação ao que ocorria do outro lado do Atlântico, na civilizada Europa (PREFEITURA DO RIO DE JANEIRO, 2002), sendo a imagem de Paris o objeto de desejo da elite carioca. Mas, nos trópicos, este modelo incorporou também a valorização dos banhos de mar, os quais eram estabelecidos como estratégia de sucesso pelos agentes imobiliários pelo poder suficiente de suscitar investimentos públicos em vias de acesso às praias oceânicas, o que beneficiava uma elite atraída por esta externalidade, e capaz de pagar por ela, o que consolidou o novo eixo de ocupação da zona sul da cidade - a qual se abriu no início do século XX com o acesso ao areal na orla de Copacabana (ARAÚJO, 1993).

\section{Copacabana: o paradigma}

É nesse cenário que o caso de Copacabana faz sentido para a discussão sobre o projeto APAC. É lugar comum afirmar que a história de Copacabana narra como em menos de meio século um areal inóspito se tornou um dos pontos turísticos mais conhecidos do planeta.

Há, porém, outro aspecto importante nessa rápida transformação: depois de poucas décadas de uma ocupação esparsa e elitizada, o acesso a novos moradores, favorecido pelas políticas de transporte e pela legislação sobre o uso do solo urbano, resultou na transformação de Copacabana no bairro mais denso da zona sul do Rio de Janeiro (ABREU, 1987; REGINENSI, 2009; FURTADO \& REZENDE, 2008). Em 1915, a densidade de Copacabana era de 2.816 habitantes por $\mathrm{km}^{2}$, e as taxas de crescimento foram de 46\%, entre 1940 e 1950 , e de 86\%, entre 1950 e 1960 . Ambos os períodos apresentaram a maior taxa para os bairros da zona sul. O número de moradores passou de 22.761, em 1920, para 74.133, em 1940, 129.249, em 1950, e 240.347 em 1960 (ABREU, 1987, pp. 81, 109, 117). Em 2010, a população do bairro era de 146.000 e para 2013 a população estimada era de 150.000 , com densidade demográfica de cerca de 30.000 habitantes por km² (IBGE, 2010). 
A experiência do bairro de Copacabana que, a partir da inauguração do Hotel Copacabana Palace, em 1923, passou a ser definitivamente associado à ideia de luxo, requinte e ponto de convergência da alta sociedade, é exemplo das possibilidades de mudanças favorecidas pela legislação referente ao uso do solo urbano. Desde a inauguração do hotel, príncipes, personalidades de destaque e atrizes hospedaram-se nele. A imagem do bairro passou a ser associada ao Copa ${ }^{6}$. Nos anos de 1930 os cassinos ganharam fama e davam ao bairro a ideia de riqueza, glamour e entretenimento, permanecendo este glamour mesmo quando os cassinos acabaram em 1946 (CARDOSO et al., 1986).

Entre 1940 e 1960, a alta taxa de crescimento da população no bairro foi possível pela verticalização das moradias, facilitada a partir de 1946, quando a Prefeitura Municipal liberou gabaritos dos prédios de Copacabana para oito, 10 ou 12 andares o que resultou na rápida e quase total substituição dos imóveis das décadas anteriores (ABREU, op.cit., p.126; CARDOSO et al., 1986). Mas, esse processo favoreceu também a construção de edifícios com grande número de pequenos apartamentos, acessíveis a uma classe média baixa atraída pelas facilidades oferecidas pelo bairro e pelo status de partilhar o espaço tradicionalmente ocupado pela elite da cidade (VELHO, 1973). Como bem percebeu Abreu (1987, p.129)

a 'democratização' de Copacabana teve dois efeitos importantes sobre o restante da zona sul. Em primeiro lugar, resultou na contenção do crescimento vertical dos demais bairros oceânicos (,,). Em segundo lugar, estimulou a transferência das classes mais abastadas para áreas menos acessíveis.

Em síntese, com uma imagem ligada a ideias como elegância, luxo, brasilidade, cosmopolitismo, corpos bronzeados e modernidade praiana, Copacabana começou a crescer verticalmente a partir da década de 1930. No final dos anos 1950, sua população atingia quase 130 mil habitantes. As luxuosas casas do bairro em pouco mais de duas décadas deram lugar aos edifícios, com apartamentos cada vez menores, que abrigavam moradores oriundos dos mais diversos lugares da cidade.

Também proliferaram butiques, cinemas, teatros, bares, restaurantes, novos hotéis e lojas de todo tipo, "impregnando o bairro com uma atmosfera alegre e contemporânea” (PIMENTEL, 2014). Em poucas décadas, Copacabana passou do glamour de um lugar privilegiado das elites para a condição de lugar da classe média, do lazer diurno e noturno de toda a metrópole e dos turistas nacionais e internacionais (COPACABANA EM FOCO, 2007).

\footnotetext{
${ }^{6}$ Modo coloquial de se referir ao Hotel Copacabana Palace, especialmente no seu período áureo.
} 


\section{Nas teias da cultura como patrimônio social}

A preocupação com a preservação do patrimônio histórico cultural no Brasil iniciou-se na primeira metade do século XX, na esteira das aspirações nacionalistas e desenvolvimentistas. Muitas das iniciativas de preservação do que seria o patrimônio nacional, justificadas por uma retórica da perda, foram assumidas pela elite intelectual. É nesse sentido que a perda e a urgência do resgate do patrimônio de arte e história nacionais foram os motivos levantados para a criação do SPHAN ${ }^{7}$ em 1936 (GONÇALVES, 1996, p. 89). O problema era tratado na escala federal e a atenção voltada para o que seria o patrimônio histórico e cultural da nação; mas a discussão sobre a importância do patrimônio, memória e história repercutiu, nas décadas seguintes, na preocupação com a memória urbana através da formulação de políticas pelos gestores das cidades. Criado em 1937, com a sigla SPHAN (Serviço do Patrimônio Histórico e Artístico Nacional), o atual IPHAN (Instituto do Patrimônio Histórico e Artístico Nacional) passou por diferentes denominações. A atuação do IPHAN, desde a sua criação, tem influenciado as políticas públicas de urbanismo e o entendimento das comunidades urbanas e dos cidadãos, especialmente os intelectuais, sobre o valor das cidades como patrimônio (MOTTA, 2002; GONÇALVES, 2002; RIBEIRO, 2007).

No Rio de Janeiro, cuja história urbanística foi uma sucessão de construções e destruições (PREFEITURA, 2002), em 1979, iniciativas da Prefeitura resultaram no Projeto Corredor Cultural, elaborado por intelectuais e técnicos da gestão municipal, que definiu estratégias de preservação associadas a ações de revitalização de atividades culturais e de recreação de um conjunto urbano. A ideia era preservar os imóveis antigos de parte da área central da cidade através da revalorização do seu uso, não apenas pelos moradores, mas também por outros seguimentos da cidade ou de fora dela (MACEDO, s/d). Em 1984, o Corredor Cultural foi criado por decreto, inaugurando a primeira fase de uma política de intervenção na cidade com objetivo de ir além da preservação apenas do patrimônio físico.

A Constituição de $1988^{8}$ veio ao encontro dessa nova demanda, ao estabelecer que o patrimônio público não seja composto exclusivamente de bens materiais (prédios históricos etc.), mas também por bens imateriais. Estava aberta a via institucional para políticas mais ousadas de preservação na cidade. Ainda em 1988, mais três bairros do centro histórico do Rio de Janeiro ${ }^{9}$ : Saúde, Gamboa, Santo Cristo, cujas iniciais foram utilizadas para formar a sigla SAGAS, além de parte do Centro, foram incluídos na política de preservação.

\footnotetext{
${ }^{7}$ Serviço do Patrimônio Histórico Artístico e Nacional.

${ }^{8}$ A função social da propriedade foi definida na Constituição de 1934, o que possibilitou a política de patrimônio com poder de intervir no direito privado da propriedade (ver RIBEIRO, 2007).

${ }^{9}$ Decreto $n^{0} 7351 / 1988$.
} 
Mas, “foi em $1992^{10}$ que se estabeleceram os alicerces para uma política pública clara e efetiva de proteção do patrimônio cultural instituindo a Área de Proteção do Ambiente Cultural - APAC ${ }^{11}$, instrumento utilizado para a proteção do ambiente construído" (RIOPREFEITURA, s/d). A esse respeito, a Prefeitura, naquele período, declara que

vem trabalhando para aperfeiçoar as APACs como forma de contribuir para a formação da memória de uma cidade moderna. A sigla (...) significa que o olhar do Patrimônio Cultural não está focado apenas nos prédios e monumentos notáveis de nossa história, mas também na preservação de conjuntos urbanos representativos das diversas fases de ocupação de nossa cidade (RIOPREFEITURA, s/d).

A justificativa é que

na formação da identidade cultural urbana entra uma complexa série de ingredientes que tornam cada bairro único e familiar aos seus moradores e frequentadores. Preservar esse ambiente, sua paisagem e fisionomia aproximam o patrimônio do cotidiano da cidade e da vida de seus habitantes. E representa a parceria do poder público com a comunidade - que em diversas ocasiões inicia o processo de discussão e reivindica proteção da memória edificada de seu bairro - para a manutenção da qualidade de vida e à participação no planejamento da cidade.

O documento da Prefeitura acrescenta, ainda, que,

em uma APAC, independente do valor individual deste ou daquele imóvel, o que importa é o valor de conjunto. (...). A proposta de proteção de uma área é precedida de um estudo da evolução urbana do lugar, mapeando sua forma de ocupação e seu patrimônio edificado, bem como as relações que os imóveis, logradouros e atividades ali desenvolvidas estabelecem entre si (RIOPREFEITURA, s/d).

\section{Por que APAC no bairro do Leblon?}

Para compreender o bairro do Leblon como um estudo de caso apropriado aos conflitos que a implantação da APAC no bairro fez emergir, vale à pena recuperar

\footnotetext{
${ }^{10}$ Plano Diretor Decenal, Lei Complementar no 16/1992.

${ }^{11}$ Plano Diretor Decenal, Lei Complementar no 16/1992.
} 
muito sucintamente a história do bairro. Com a expansão imobiliária de Copacabana e Ipanema, que favoreceu a chegada de uma classe média menos abastada, as classes ricas recuaram para áreas mais afastadas e não servidas por transporte público, entre elas, o extremo oeste do Leblon, especialmente nas partes mais altas cujo acesso deveria ser de automóvel (BERNARDES, 1961; ABREU, 1987). Essa ocupação começou entre 1920 e 1922 e a mais efetiva, nas áreas planas, intensificou-se a partir da década de 1930.

Com a melhoria na acessibilidade à parte plana, a heterogeneidade social foi a norma desde os primórdios da ocupação, ou seja, classes ricas nas casas (bangalôs) da orla e nas partes altas, e a classe média nos prédios baixos. Na década de 1940, ao contrário do que acontecia em Copacabana, ainda havia pouca verticalização. Mas, como acontecia em toda a cidade, os pobres procuravam a proximidade do mercado de trabalho oferecido pelos serviços prestados para as classes de melhor poder aquisitivo e instalavam-se nas áreas mais insalubres e desvalorizadas, formando favelas, como foi o caso também no Leblon. No final da década de 1960, coexistiam no bairro a Cruzada São Sebastião, conjunto de 10 blocos de apartamentos construído para abrigar moradores removidos de duas favelas da orla da Lagoa Rodrigo de Freitas; o Conjunto dos Jornalistas, composto de três grandes edifícios, construído pelo IAPC ${ }^{12}$, que destinou a maior parte das unidades aos jornalistas, além de ex-pracinhas e comerciários ${ }^{13}$; juntamente às classes média e rica, esta na parte alta, nas poucas casas que ainda resistiam e nos apartamentos de luxo que começavam a surgir.

Durante a década de 1970, a verticalização e a especulação imobiliária aceleraram-se. Alguns imóveis do período de 1940 a 1960, considerados pelos moradores como elementos de identidade do bairro, foram demolidos para a construção de prédios mais altos. Este processo de adensamento do bairro teve como ícone o conjunto de edifícios denominado Selva de Pedra, um quadrilátero com quatro pequenas ruas sem saída de acesso e uma praça arborizada no centro, construído em terreno antes ocupado por uma favela, cujos apartamentos foram comprados por militares e outros profissionais da classe média.

É nesse cenário que, na década de 1980, grupos de interesse se organizam para evitar que as mudanças ocorridas em outros bairros, especialmente em Copacabana, se repetissem no Leblon. A Prefeitura atende a tal demanda e, progressivamente, estabelece a restrição do gabarito dos prédios, tombando imóveis antigos. Mas, sob o risco da corrida de incorporadores imobiliários para o bairro, é decretada a APAC Leblon em 2001 por meio, dentre outras medidas, da lista de 218 imóveis preservados. O objetivo foi de "estabelecer as bases para a [sua] ocupação, segundo

\footnotetext{
${ }^{12}$ Instituto de Pensão e Aposentadoria dos Comerciários.
} 
as normas vigentes de conservação do patrimônio arquitetônico, preservando os vestígios físicos, históricos e sociais, que contribuíram para a sua formação" (LOPEZ, s/d). Uma clamorosa batalha judicial seguiu-se ao decreto.

Como se pode ver, a ocupação do Leblon seguiu os passos de Copacabana e de Ipanema, com defasagem de poucas décadas. Qual seria então a especificidade que levou ao debate acalorado após a criação da APAC? A evidência primeira é que, ao contrário do centro antigo da cidade ocupado por imóveis, em muitos casos, degradados e por uma população de baixa renda, as ações de proteção do patrimônio cultural no Leblon, o metro quadrado mais caro da cidade, confrontaram-se diretamente com os interesses dos empreendedores imobiliários e dos proprietários de imóveis antigos que viam a possibilidade de vendê-los a bom preço e indiretamente com potenciais interessados em residir no bairro. A retórica do bairro como lugar de uma cultura própria a ser preservada elaborada de modo competente por intelectuais de diferentes áreas, se, por um lado, buscou sensibilizar o poder público para atuar na sua preservação em nome da qualidade de vida na cidade, por outro, reforçou a percepção do elitismo excludente característico de um bairro de elite e, paradoxalmente, contribuiu para a especulação imobiliária. Afinal, em muitos textos sobre a história do Leblon são destacados os hábitos das famílias abastadas que nele se instalavam.

Deve ser ressaltado que toda justificativa para a ação de preservação do patrimônio, material ou imaterial, é intelectual e, portanto, de uma minoria que fala em nome da maioria. Este é um primeiro ponto de partida para compreender o conflito de interesses que toda ação contra o direito de propriedade em sociedades liberais, moldadas pelo direito individual, deve enfrentar quando se trata de definir limites para esse direito frente ao bem da coletividade. O problema é o confronto entre a objetividade do que seria o direito legal de propriedade e a intangibilidade e subjetividade da ideia de bem coletivo. Parece que, em termos bem gerais, é disto que se trata quando as APACs são o tema.

Para demarcar a questão da subjetividade no conceito de bem coletivo, Velho (2006, p. 237) destaca, no debate de 1984,

o tombamento como patrimônio cultural do terreiro de candomblé Casa Branca, em Salvador, a atuação de um verdadeiro movimento social (...) reunindo artistas, intelectuais, jornalistas, políticos e lideranças religiosas que se empenharam a fundo na campanha pelo reconhecimento do patrimônio afrobaiano. (...) Foi necessário um esforço muito grande de um grupo de conselheiros, do próprio secretário de cultura do MEC e de setores da sociedade civil para que afinal fosse obtido sucesso.

Nos argumentos para o tombamento, o autor destaca "o papel crucial na área da sociabilidade e do convívio dentro das camadas populares e entre estas e outros 
segmentos sociais” (VELHO, 2006, p. 239). Há no texto a referência ao papel dos intelectuais e o valor intangível contido nas ideias de sociabilidade e convívio.

No caso do Leblon, alguns termos do debate sobre as mudanças ocorridas e sobre a ação da Prefeitura ajudam a identificar atores, interesses e o peso de cada um nessas ações. Procuramos apresentar os termos da defesa e da crítica por atores sociais diretamente afetados. Entre os que defendem, estão os intelectuais, os artistas e os moradores que não querem o que chamam de copacabanização do bairro. A crítica vem dos empreendedores imobiliários e dos proprietários dos imóveis afetados pelo decreto da Prefeitura.

Uma primeira narrativa é do autor do livro O Antigo Leblon - uma aldeia encantada (LIMA, 1999), antigo morador que se vê compelido a defender o bairro e todo o imaginário construído em torno dele. O texto inicia com a crítica a um jornalista que não sabia o nome antigo de uma rua, mas conhecia uma delicatessen famosa pelos altos preços e frequência seleta e lança sua diatribe: "desconhece a história do bairro, mas sabe o nome do empório, com fumaças de grã-finismo, plantado nas proximidades para abastecer a vulgaridade ostentosa do nouveaurichismo itinerante". O autor, interessado na história do bairro onde sua família residia desde 1935, percebeu no desconhecimento "mais do que outro sintoma episódico da rotineira e acintosa inversão de valores, a sedimentação da soberba fatuidade do predador arrivista que, de há muito, vem desfigurando o Leblon, conspurcando suas venerandas tradições...”. E decide contar a "história da gente simples e divertida que viveu cá por estes sítios, nos anos 40 e 50” (LIMA, 1999).

Ao finalizar sua história, o autor reconhece que o crescimento urbano é inevitável, "mas no caso do Leblon, o preço pago pela subversão foi excessivo: custou-nos o precioso cantinho, prazeroso, amorável”. E não deixa de criticar “a voragem deformadora [que] transformou o bairro ao jeito do charivari de mau gosto de Copacabana”. Aponta também dois fatores que "concorreram para sedimentar esse deplorável processo: a ocupação da Selva de Pedra, por forasteiros aspirantes à classe média e a apropriação dos bares, pela intelligentsia inquieta, cansada de baldear por Copacabana e Ipanema” (LIMA, 1999, p. 137). O saudosismo, o conservadorismo e a xenofobia são evidentes, mas representativos de uma parcela dos antigos moradores identificados com o que seria uma classe média culta, a qual valoriza o modo de vida enquanto valor intangível, guardadas as devidas proporções, é claro, à linha da preservação dos bens imateriais que inspira as APACs.

Ainda no componente intelectual do valor subjetivo implícito à ideia de patrimônio, recorro a Artur da Távola (2008), conhecido formador de opinião já falecido, jornalista, intelectual e político, que declara:

o patrimônio público não é composto exclusivamente de bens materiais (prédios históricos etc.) é composto igualmente de bens 
imateriais que não se mensuram por valor pecuniário e, sim, por valor subjetivo. Ambiente cultural significa um lugar, bairro ou logradouro no qual ainda existe qualidade de vida. Isso também faz parte do patrimônio público. Em 2001, o Leblon foi considerado um desses locais de qualidade de vida, ainda não deteriorados por edifícios descomunais. E é verdade. Por isso, foi escolhido para ser a primeira APAC. Há seis anos o bairro está em paz com seu meio ambiente. A especulação imobiliária chiou e tudo fez para derrubar a medida. Mas, com o apoio do prefeito (,,), creio que trinta outras APACs foram criadas em bairros da cidade, depois do Leblon. Uma atitude de grandeza.

Continuando, o autor acrescenta:

esta é uma das maiores vitórias da inteligência sobre a voracidade da especulação imobiliária e o crescimento vertiginoso que vitimou Copacabana, por exemplo. As principais cidades do mundo possuem APACs, com nomes diferentes, e se defendem para não verem desaparecer o seu estilo de vida em nome de uma pseudo-modernização. Vide Paris (TÁVVOLA, 2008).

Contra o projeto APAC encontram-se dois grupos negativamente afetados: moradores dos imóveis antigos “apacados" e agentes imobiliários, além de acadêmicos que criticam o fato de a Prefeitura não ter consultado a população previamente. A APAC do Leblon foi objeto de exaustiva tese de doutorado (CARLOS, 2008) na qual o autor, mesmo destacando a corrida imobiliária no bairro em 2001 e reconhecendo que por isso "a prefeitura criou uma APAC para o bairro em tempo recorde, ou seja, um mês”, critica a falta de respaldo ou discussão popular. Acrescenta que a medida foi amplamente justificada, através da mídia carioca, pelos temores de uma possível "onda de especulação viabilizada pela Lei 41/99”. Mas o trabalho explora a insatisfação dos proprietários afetados pelo projeto da Prefeitura e suas fundamentações para as ações judiciais contra ela, juntamente com os incorporadores imobiliários.

Após a decretação da APAC iniciou-se uma batalha judicial entre proprietários de imóveis preservados e a prefeitura, em busca do resgate da 'garantia do direito de propriedade' que, segundo os reclamantes, teria sido violado em face do impedimento legal da demolição. Ações populares foram impetradas (...) por associações locais lideradas pela Associação de Proprietários de Pequenos Prédios (APPP), criada após a decretação da APACLeblon (CARLOS, 2008 p. 228). 
$\mathrm{O}$ argumento dos moradores afetados negativamente coloca frente a frente o valor material de seu patrimônio e a intangibilidade do patrimônio cultural. Mas há, ainda na tese, a perspectiva do cientista social em oposição à dos intelectuais que embasaram os argumentos da Prefeitura. Para o autor,

seria o lado perverso de uma política de proteção do patrimônio cultural realizada às avessas, ou seja, sem o devido embasamento teórico e uma ampla discussão com a sociedade civil organizada. (...) a forma autoritária adotada pela prefeitura, na proteção não apenas no bairro do Leblon, mas de todas as demais APACs estabelecidas a partir de 2001, revela uma leitura da cidade cada vez mais distanciada de sua realidade social e econômica. Técnicos do órgão executivo do patrimônio cultural municipal limitam-se à importante, mas não suficiente tarefa de estudar arquiteturas pretéritas prescindindo dos atuais interesses e necessidades coletivas de comunidades locais (CARLOS, 2008, p. 233).

A Associação de Dirigentes de Empresas do Mercado Imobiliário - ADEMI, por sua vez, chama a atenção para a depreciação de imóveis preservados e coloca em confronto o valor histórico e cultural dos bens e seu preço de venda. Para o setor,

conservar valor arquitetônico ou cultural não é garantia de boa condição de venda para um imóvel. Isso é o que proprietários de edifícios preservados ou tombados pelas Áreas de Preservação ao Ambiente Cultural (APACs) constataram desde 2001, quando a gestão do governo (...) iniciou na cidade sua política preservacionista. As restrições impostas aos prédios protegidos geram receios nos potenciais compradores e derrubam a liquidez dos imóveis (ADEMI, 2005).

Em 2010, matéria no $O$ Globo online destaca que "Casas fora da APAC são cobiçadas por construtoras”. De acordo com a matéria, as casas da praia ou próximas a ela não são os únicos alvos do mercado imobiliário no Leblon. Com os espaços para construção ficando cada vez mais escassos no bairro, os olhos das construtoras têm se voltado aos pequenos prédios não protegidos pela APAC. No artigo, o presidente da CONCAL ${ }^{13}$ informa que de 50 a 60 pequenos imóveis multifamiliares são considerados hoje potenciais negócios futuros. Eles reúnem condições favoráveis por não contarem com garagens ou elevadores, acumularem problemas de conservação ou dívidas em tributos ou terem proprietários mais permeáveis a negociações. Só a CONCAL ergue, no momento, cinco obras, das

\footnotetext{
${ }^{13}$ Empreendimentos imobiliários.
} 
quais quatro são no Leblon e uma em Ipanema. E está em negociação avançada com os donos de outros três imóveis.

As ações da Prefeitura, se foram capazes de reduzir o ritmo de verticalização e de adensamento do bairro, não foram consensuais nem reduziram a especulação imobiliária que agora, no embalo do discurso sobre suas qualidades urbanísticas, vem aumentando o valor do metro quadrado para compra e para aluguel. As ações judiciais não terminaram e o risco de voltar ao status quo anterior não desapareceu.

\section{Finalizando: quem ganha e quem perde na APAC Leblon?}

O processo de patrimonialização, já amplamente discutido, propõe proteger a cultura frente à força das mudanças impostas pela ordem econômica. Nesse sentido, a própria ideia de atribuir a um bem um valor cultural, nomeá-lo patrimônio e tomar a decisão de preservá-lo supõe contrariar interesses, presentes ou futuros. Há, portanto, na política de patrimonialização um paradoxo implícito: proteger um bem cultural de uma sociedade, ou seja, favorecer a preservação da sua memória como um valor que não tem equivalência monetária, impacta, de modo positivo ou negativo, o valor econômico deste mesmo bem e, consequentemente, aquele do patrimônio privado do cidadão. Dessa maneira, longe de ser neutra, a política de patrimonialização envolve interesses e conflitos, como aqueles vistos até aqui.

Em 2011, os termos da patrimonialização no Leblon foram ampliados para incluir a preservação das práticas e costumes do "modus vivendi carioca”, reforçando o conteúdo intangível da cultura e exigindo de novas atividades a permissão da Secretaria de Patrimônio Cultural da Prefeitura para não descaracterizar a "identidade carioca" do bairro. O confronto de interesses entre atividades econômicas e a Prefeitura emergiu nesta segunda fase.

É interessante que no Leblon, onde se localiza o metro quadrado mais caro da cidade, misturam-se antigos moradores - saudosos do tempo em que o bairro era chamado por eles de "aldeia encantada" - e os novos habitantes, atraídos não apenas pelos serviços locais, mas também pela aura de glamour folhetinesco adquirido depois de o bairro ter sido cenário de algumas novelas de conhecido autor que nele reside. Também por ser endereço de algumas celebridades da maior rede de TV do país.

O decreto de 2001 visava, sobretudo, frear o processo de expansão imobiliária do bairro, cujo valor elevado do metro quadrado compensava a compra dos pequenos edifícios antigos, agora tombados ou protegidos, do tempo da aldeia encantada, a fim de substituí-los por outros - destinados aos novos moradores ricos. A valorização do bairro, no entanto, favorecia a capitalização destes antigos proprietários típicos de uma classe média pouco abastada através das ofertas feitas pelos seus imóveis, inflacionadas pelos incorporadores imobiliários. 
Em 2011, a extensão da patrimonialização às atividades, especialmente as comerciais, ao contrário, favoreceu o comerciante tradicional. O conflito é inevitável e opõe antigos moradores que querem preservar sua "aldeia" àqueles que querem se capitalizar; os antigos comerciantes, que conservam seus botequins e bazares, aos novos moradores que preferem os cafés e os restaurantes de luxo; o capital imobiliário, que procura espaço para investimentos lucrativos, aos defensores do status quo. Na política local, o dissenso alimenta o debate na Câmara Municipal, e os grupos de pressão se organizam. Os decretos são importantes por revelar que, até o momento, a Prefeitura - enquanto representante dos interesses difusos de associações de moradores e de formadores de opinião - está vencendo. Embora não se saiba até quando.

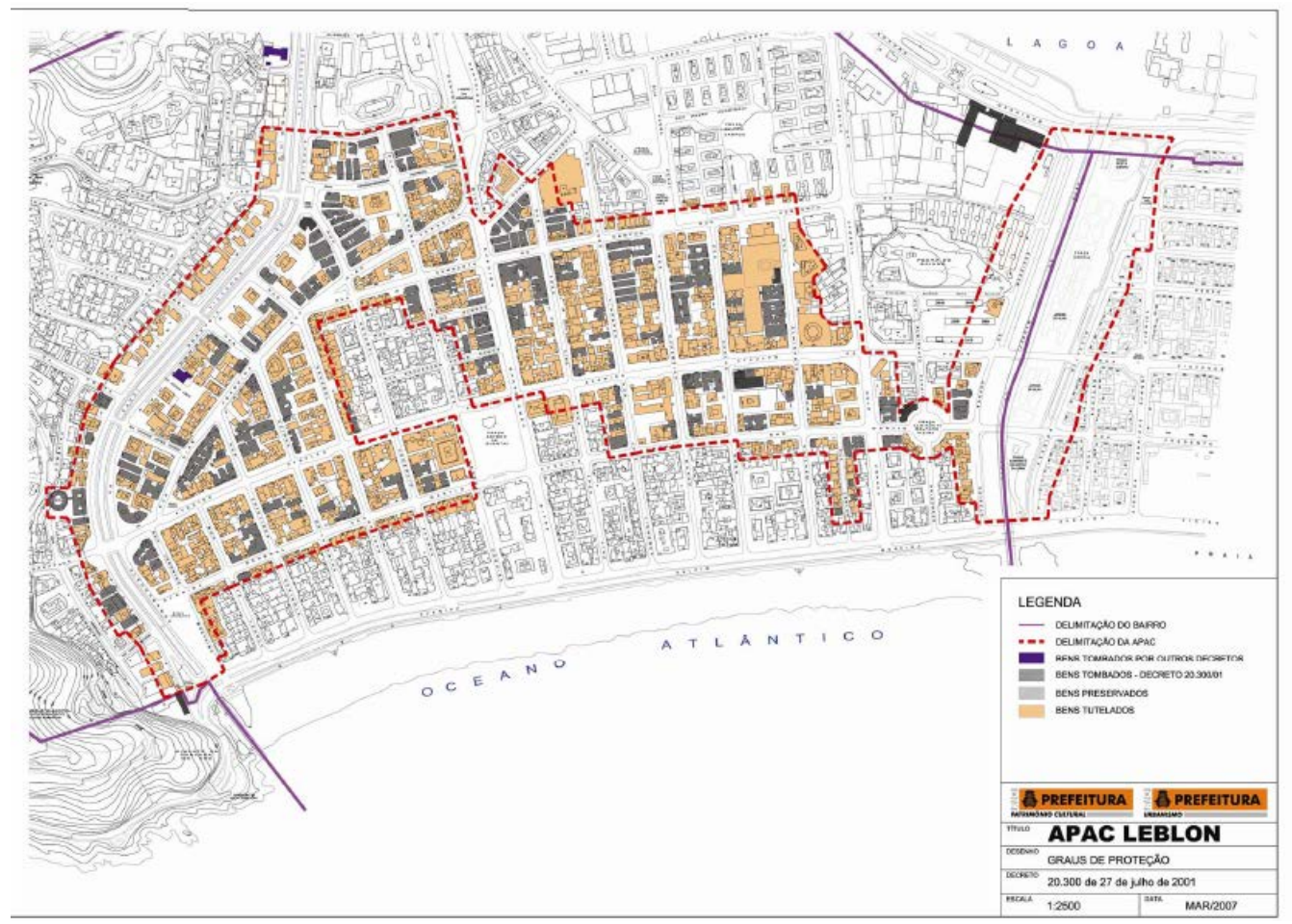

Figura 1: Mapa do Leblon com os bens tombados e protegidos.

Fonte: Prefeitura do Rio de Janeiro. Disponível em: <http://www0.rio.gov.br/mapa_da_da_apac.pdf>. Acessado em: jan. 2015.

Numa sociedade de urbanização acelerada, com gestões urbanas historicamente submetidas à lógica dos interesses do capital imobiliário, a possibilidade de colocar em ação novos interesses e trazer ao debate os limites do direito individual sobre a propriedade privada frente ao interesse coletivo é, certamente, um avanço. A democracia é a moldura institucional para o debate no país, e a política a garantia de que não deve haver vitoriosos ou perdedores absolutos. Cada um ganha e perde um 
pouco, o que fica evidente no mapa de distribuição dos imóveis da APAC - Leblon, ilustrado na Figura 1. Nos quarteirões mais próximos à orla, os mais caros, quase não há imóveis “apacados”. Se há política em jogo, não é possível ganhar tudo.

\section{Bibliografia}

ABREU, M. de A. (1987) Evolução urbana do Rio de Janeiro. IPP/Rio de Janeiro. ADEML (2005) Proteção derruba valor. Jornal do Brasil, 24/jul/. Disponível em: http://www.ademi.org.br/article.php3?id_article=9873 Acessado em: jan. 2015. ÂNGULO, A. A. (2015) A outorga onerosa do direito de construir e o patrimônio cultural. Revista Museu. Edição brasileira. Disponível em: $<$ http://www.revistamuseu.com.br/artigos/art_.asp?id=12817>. Acessado em: jan. 2015.

BRESCIANI, M. S. (2002) Cidade e história. In: OLIVEIRA, L. L. (Org.) Cidade: história e desafios. Rio de Janeiro: Ed. Fundação Getúlio Vargas. pp. 16-35.

CARDOSO, E. D. et al. (1986) História dos Bairros, memória urbana: Copacabana. Rio de Janeiro: João Fortes Engenharia / Index.

CASTRO, I. E. (2011) Geografia e Política. Território, escalas de ação e instituições. 4ed. Rio de Janeiro: Bertrand Brasil.

COPACABANA EM FOCO (Blog) (2008) Disponível em: https://ama2345decopacabana.wordpress.com/o-templo-do-glamour-o-copa/

Acessado em: jan. de 2015.

GOMES, P. C. C. (1996) Geografia e modernidade. Rio de Janeiro: Bertrand Brasil. GONÇALVES, J. R. S. (2002) Monumentalidade e cotidiano: os patrimônios culturais como gênero de discurso. In: OLIVEIRA, L. L.(Org.). Cidade: história e desafios. Rio de Janeiro: Ed. Fundação Getulio Vargas. pp.108-123.

. (1996) A retórica da perda. Os discursos do patrimônio cultural no Brasil.

Rio de Janeiro: Ed. UFRJ.

FURTADO, F.; REZENDE, V. L. F. M. (2008) Discursos e imagens acerca de intervenções urbanas no Rio de Janeiro (1920-1940): a questão da valorização fundiária em planos e projetos urbanos. Revista de Pesquisa em Arquitetura e Urbanismo, EESC-USP, 8/2. São Paulo. pp.115-125.

LIMA, R. B. (1999) O antigo Leblon. Uma aldeia encantada. Rio de Janeiro: Antigo Leblon.

LOPEZ, V. (s/d) Leblon. A história do bairro. Disponível em https://vanesalopez.wordpress.com/pesquisas/leblon/. Acessado em: jan. 2015.

MACEDO, M. A. M. (2004) A concepção do projeto corredor cultural do Rio de Janeiro: a participação de técnicos e intelectuais no processo de planejamento urbano. Seminário de História da Cidade e do Urbanismo, nº4, v. 8. pp. 1-15. Disponível em: http://unuhospedagem.com.br/revista/rbeur/index.php/shcu/article/view/1053/1028. 
MOTTA, L. (2002) Cidades mineiras e o IPHAN. In: OLIVEIRA, L. L. (Org.) Cidade: história e desafios. Rio de Janeiro: Ed. Fundação Getúlio Vargas. pp.124139.

O GLOBO (2010) Leblon perde mais uma casa para construção de prédio de apartamentos de até $\mathrm{R} \$$ 6,5 milhões. Disponível em $<$ http://oglobo.globo.com/rio/leblon-perde-mais-uma-casa-para-construcao-depredio-com-apartamentos-de-ate-65-milhoes-2923373> Acessado em janeiro de 2015.

OLIVEIRA, L. L. (2002) Memórias do Rio de Janeiro. In: OLIVEIRA, L. L.(org.) Cidade: história e desafios. Rio de Janeiro: Ed. Fundação Getulio Vargas. pp. 156174.

PIMENTEL, M. (2014) Copacabana: de bucólico areal a um dos réveillons mais badalados do planeta. MultiRio. Disponível em: $<$ http://www.multirio.rj.gov.br/index.php?option=com_content\&view=article\&id=1 390>. Acessado em: jan. de 1015.

PINHEIRO, A. I. F. (2002) Aprendendo com o patrimônio. In: OLIVEIRA, L. L. (Org.). Cidade: história e desafios. Rio de Janeiro: Ed. Fundação Getulio Vargas. pp.140-155.

REGINENSI, C. (2009) Desenvolvimento (in)sustentável na orla de Copacabana (Rio de Janeiro): Atores, recursos e processo participativo. Revista Desenvolvimento Social, $\mathrm{n}^{\circ}$ 3. Montes Claros. pp.1-20.

RIBEIRO, R. W. (2007) Paisagem cultural e patrimônio. Rio de Janeiro: IPHAN. RIO DE JANEIRO. (2002) Prefeitura Municipal do Rio de Janeiro. Secretaria das Culturas/ Arquivo da Cidade. Memória da destruição. Rio - Uma história que se perdeu (1889-1965).

RIO DE JANEIRO. (s/d) Prefeitura Municipal do Rio de Janeiro. Área de Proteção do Ambiente Cultural (APAC). Disponível em: $<$ www0.rio.rj.gov.br/patrimonio/apac.shtm>. Acessado em: jan. 2015.

RIO DE JANEIRO. (s/d) Prefeitura Municipal do Rio de Janeiro. SAGAS. Disponível

em:

$<$ http://www0.rio.rj.gov.br/patrimonio/pastas/legislacao/release_sagas.pdf $>$.

Acessado em: jan. 2015.

SIMAY, P. (1989) La ville des sens. Préface, Simmel, Georg. Les grandes villes et lavie de l'esprit. Paris: Payot. pp.7-36.

SIMMEL, G. (1989) Les grandes villes et $l$ avie de l'esprit. Paris : Payot.

TÁVOLA, A. (2008) Em defesa da APAC, 05. mar. Disponível em: $<$ https://apacviva.wordpress.com/>. Acessado em: jan. 2015.

VELHO, G. (1973) A utopia urbana. Rio de Janeiro: Zahar. . (2006) Patrimônio, negociação e conflito. Mana 12(1). pp. 237-248. 